\title{
How affordable is healthy eating?
}

\author{
V. M. Ross, C. M. O’Brien, S. J. Burke, G. P. Faulkner and M. A. T. Flynn \\ Food Safety Authority of Ireland, Lower Abbey St, Dublin 1, Republic of Ireland
}

Socio-economic disadvantage is associated with a higher risk of chronic disease ${ }^{(1)}$. This factor underpins the necessity to ensure that key population-based preventive strategies, such as healthy eating, are affordable. The purpose of the present paper is to examine the cost of healthy eating in Ireland and the implications for those receiving Social Welfare Allowances.

'Healthy eating' was defined according to well-established quantitative nutrient goals ${ }^{(2)}$. Based on these goals, eighty-eight daily food patterns were developed to meet the energy requirements of twenty-two individuals representing males and females within four agegroups $(5-13,14-18,19-50$ and $\geq 51$ years). These food intake patterns were used to develop population-based food guidance on healthy eating for those aged $>5$ years in Ireland. Data from the Central Statistics Office was used to describe the composition of the four most typical households in Ireland ${ }^{(3)}$. Using the daily food patterns developed for healthy eating, the weekly food requirements of these households were priced in three different grocery store chain outlets to determine the range of overall cost of healthy eating. Shown in the Table are the percentages of the minimum and maximum weekly cost (described for six food groups) according to Social Welfare (Department of Social and Family Affairs, personal communication) income for four typical households in Ireland.

\begin{tabular}{|c|c|c|c|c|}
\hline \multirow[b]{2}{*}{ Household. ... } & \multicolumn{4}{|c|}{ Overall weekly cost range $(\%)$} \\
\hline & $1^{*}$ & $2 \dagger$ & $3 \ddagger$ & $4 \S$ \\
\hline Bread, cereals and potatoes & $12-15$ & $11-12$ & $11-17$ & $10-12$ \\
\hline Dairy & $18-20$ & $12-16$ & $16-24$ & $16-19$ \\
\hline Meat, fish and alternatives & $29-30$ & $32-35$ & $25-31$ & $29-33$ \\
\hline Fruit and vegetables & $28-33$ & $31-35$ & $27-35$ & $31-37$ \\
\hline Fats and oils & $1-4$ & $2-3$ & $1-4$ & $2-4$ \\
\hline Snacks and miscellaneous & $4-5$ & $3-5$ & $4-5$ & $2-3$ \\
\hline Total weekly cost range $(€)$ & $123-273$ & $70-165$ & $29-58$ & $49-116$ \\
\hline$\%$ Social Welfare Allowance & $31-70$ & $21-49$ & $13-25$ & $21-51$ \\
\hline
\end{tabular}

The cost of healthy eating for typical households in Ireland ranges from a minimum of $13-31 \%$ and a maximum of $25-70 \%$ of the Social Welfare Allowance depending on which grocery store is used. The cost of healthy eating for households with children represents the largest percentage of the Social Welfare Allowance. This Allowance must cover all other living expenses including rent and utilities, making healthy eating less attainable for families with children, particularly those with teenagers. Fruit and vegetables and meat, fish and alternatives were found to be the most expensive food items. This finding indicates that the biggest challenges for healthy eating among low-income families may relate to achieving recommended intakes of these foods in particular.

Measures to provide for the expense of healthy eating are necessary for families depending on the Social Welfare Allowance in Ireland. Special provisions should be made for families with older children and teenagers. This provision could include schemes to provide foods from the meat group and fruit and vegetables.

1. James WPT, Nelson M, Ralph A et al. (1997) Br Med J 314, 1545-1549.

2. Institute of Medicine of the National Academies (2006) Dietary Reference Intakes The Essential Guide to Nutrient Requirements. Washington, DC: The National Academies Press.

3. Central Statistics Office (2006) Census 2006. http://www.cso.ie/ (accessed May 2009). 